Article

\title{
Diagnostic Performance of Automated SARS-CoV-2 Antigen Assay in Nasal Swab during COVID-19 Vaccination Campaign
}

\author{
Haya Altawalah ${ }^{1,2, *}$, Wadha Alfouzan ${ }^{1,3}$, Talal Al-Fadalah ${ }^{4}$ and Sayeh Ezzikouri ${ }^{5, *(D)}$ \\ 1 Department of Microbiology, Faculty of Medicine, Kuwait University, Safat 24923, Kuwait; \\ alfouzan.w@ku.edu.kw \\ 2 Virology Unit, Yacoub Behbehani Center, Sabah Hospital, Ministry of Health, Safat 24923, Kuwait \\ 3 Laboratory Medicine, Farwania Hospital, Ministry of Health, Farwania 85000, Kuwait \\ Qualities and Accreditation Directorate, Ministry of Health, Safat 13001, Kuwait; talfadalah@gmail.com \\ 5 Virology Unit, Viral Hepatitis Laboratory, Institut Pasteur du Maroc, Casablanca 20250, Morocco \\ * Correspondence: dr.altawalah@gmail.com (H.A.); sayeh.ezzikouri@pasteur.ma (S.E.)
}

Citation: Altawalah, H.; Alfouzan, W.; Al-Fadalah, T.; Ezzikouri, S. Diagnostic Performance of Automated SARS-CoV-2 Antigen Assay in Nasal Swab during COVID-19 Vaccination Campaign. Diagnostics 2021, 11, 2110. https:// doi.org/10.3390/diagnostics11112110

Academic Editor: Alessandro Russo

Received: 21 October 2021

Accepted: 11 November 2021

Published: 15 November 2021

Publisher's Note: MDPI stays neutral with regard to jurisdictional claims in published maps and institutional affiliations.

Copyright: (c) 2021 by the authors. Licensee MDPI, Basel, Switzerland. This article is an open access article distributed under the terms and conditions of the Creative Commons Attribution (CC BY) license (https:// creativecommons.org/licenses/by/ $4.0 /)$.

\begin{abstract}
Background: To control the spread of the pandemic brought about by the severe acute respiratory syndrome coronavirus 2 (SARS-CoV-2) infection, it is necessary to have an automated reliable diagnostic assay. To date, the RT-PCR (RT-qPCR) has been the recommended laboratory method to diagnose SARS-CoV-2 infection, but there is a need for more automated and reliable tests. The aim of this real-life study was to assess the diagnostic performance of DiaSorin's LIAISON SARS-CoV-2 antigen (Ag) chemiluminescence immunoassay in detecting SARS-CoV-2 in vaccinated and unvaccinated individuals. Methods: A prospective study was performed on 300 nasopharyngeal swabs randomly collected from 31 May to 6 July 2021. Nasopharyngeal samples were assayed with DiaSorin's LIAISON SARS-CoV-2 Ag and TaqPath ${ }^{\mathrm{TM}}$ COVID-19 multiplex RT-qPCR. Results: Of 300 participants, 150 had a RT-qPCR confirmed SARS-CoV-2 infection of whom $113(75.33 \%)$ were also detected by the DiaSorin LIAISON SARS-CoV-2 Ag. Taking RT-qPCR as a reference, the sensitivity and specificity of the DiaSorin LIAISON SARS-CoV-2 Ag assay were evaluated as $75.33 \%(95 \% \mathrm{CI}=67.64-82)$ and $100 \%(95 \% \mathrm{CI}=97.57-100)$, respectively. When a viral load cut-off was applied for high viral load (median cycle threshold $(\mathrm{Ct})<18.57$ ), the overall sensitivity was increased to $96.55 \%$ (95\% CI = 88.09-99.58). Interestingly, median RT-qPCR Ct and SARS-CoV-2 Ag values were similar between fully vaccinated and unvaccinated subjects. Conclusions: Automated, quantitative LIAISON SARS-CoV-2 Ag assay shows good performance to identify SARS-CoV-2infected individuals with moderate to high viral loads. LIAISON SARS-CoV-2 Ag testing could be used as frontline testing for COVID-19 diagnosis and be more suitable for large utilization.
\end{abstract}

Keywords: COVID-19; SARS-CoV2; Ag-RDT; diagnosis; rapid decisions

\section{Introduction}

Mass testing for the early identification and isolation of infectious coronavirus-19 disease (COVID-19) individuals is efficacious for reducing the disease spread [1]. In the ongoing pandemic context of COVID-19, diagnostic testing for SARS-CoV-2 is crucial in order to limit the spread of the virus as well as to appropriately manage infected patients [2]. To date, the gold standard test for severe acute respiratory syndrome coronavirus 2 (SARS-CoV-2) is the real-time RT-PCR (RT-qPCR) [3,4]. Moreover, RT-qPCR requires nasopharyngeal swabs (NPS) to be sent off to a special laboratory with specialist equipment, analyzed by competent laboratory staff and is time consuming (4-6 h), not including the time to transport the specimens to the laboratory [3]. Simpler and less expensive antigenbased tests have been developed to address these issues. However, antigen-detecting rapid diagnostic tests (Ag-RDT) require a visual readout and lack proper internal quality control, making them more prone to errors [5-7]. However, a number of automated antigendetecting diagnostic assays for SARS-CoV-2 detection are now commercially available and 
can result in rapid decisions on patient care, isolation and contact tracing at the point of care [8]. As a part of the surveillance program for pandemic control in Kuwait, the local government launched nucleic acid amplification test-based systematic screenings and several other tools in the country in order to rapidly mitigate and manage COVID-19 patients [9].

To date, comparative studies have almost been completed for Ag-RDT with RTqPCR testing and have shown high reliability before the vaccination campaign against COVID-19 [8,10-12]. COVID-19 vaccines reduce severe disease and death from SARS-CoV2 infection $[13,14]$ but breakthrough cases occur $[15,16]$. Several reports have shown no difference in terms of viral loads between vaccinated and unvaccinated subjects. However, other studies have found that COVID-19 vaccines reduce viral loads $[17,18]$. This situation emphasizes the importance to replicate other investigations in other populations. Moreover, the general application of antigen testing deserves to be further investigated and validated on larger cohorts, taking into account also the current spreading of the novel more infectious SARS-CoV-2 variants $[19,20]$. The SARS-CoV-2 variants may present important diagnostic challenges in the future. The rapid implementation of a COVID-19 antigen assay requires critical assessment. Thus, the objective of this real-life study was to evaluate a quantitative antigen assay in detecting SARS-CoV-2 in vaccinated and unvaccinated individuals. The first part of the study was to evaluate the performance of the DiaSorin LIAISON SARSCoV-2 Ag test in detecting SARS-CoV-2 compared to RT-qPCR. The second part of the study was to assess the limit of detection between SARS-CoV-2 Ag and RT-qPCR assays. The third part of the investigation was to analyze the viral loads between vaccinated and unvaccinated subjects.

\section{Materials and Methods}

\subsection{Clinical Specimens}

To collect nasopharyngeal swab specimens (NPS), the swab was passed through the nostril until reaching the posterior nasopharynx and removed while rotating as previously described [9]. NPS were collected by health-care professionals from individuals at the AnaSalbi laboratory, a certified COVID-19 testing laboratory in Kuwait. After swabbing, each absorbent swab was placed immediately into a sterile tube with copan universal transport media (UTM). We conducted a cross-sectional study from 31 May to 6 July 2021, with a nested sampling from positive and negative samples. One hundred and fifty negative and 150 positive specimens were randomly sampled from the different NPS stored in the laboratory. Metadata including demographic data, vaccination status, asymptomatic, symptomatic were collected. The study protocol was approved by the permanent Committee for Coordination of Medical and Health Research, Ministry of Health, Kuwait, and the study was conducted in accordance with the ethical guidelines of the 1975 Declaration of Helsinki as reflected in a priori approval by the institution's human research committee.

\section{2. $S A R S-C o V-2 R T-q P C R$}

Viral RNA was automatically extracted from $200 \mu \mathrm{L}$ of the NPS specimens using the MagMAX ${ }^{\mathrm{TM}}$ Viral/Pathogen II Nucleic Acid Isolation Kit (Thermo Fisher Scientific, Vilnius, Lithuania) on KingFisher (Thermo Fisher Scientific, Waltham, MA, USA) according to the manufacturer's instructions. RT-qPCR was performed using TaqPath ${ }^{\text {TM }}$ COVID-19 multiplex real-time RT-PCR test (the Orf1ab, N and S genes) (Thermo Fisher Scientific, Waltham, MA, USA) according to the manufacturer's instructions. Negative and positive controls were run simultaneously with samples [2]. The assay was performed using a QuantStudio 5 real-time PCR detection system (Thermo Fisher Scientific, Waltham, MA, USA). Test results were reported quantitatively as cycle threshold (Ct) value of the ORF1ab, the $\mathrm{N}$ and the $\mathrm{S}$ genes, while qualitative data were reported as positive/negative at test cut-off (i.e., $\mathrm{Ct}<37$ for positive or $\geq 37$ for negative samples). The $\mathrm{Ct}$ values used to classify specimens as 'high viral load', 'medium viral load' and 'low viral load' defined as previously described $[7,21]$, they were $<18.57,18.57-28.67$ and $>28.67$, respectively. 


\subsection{LIAISON SARS-CoV-2 Ag}

The DiaSorin LIAISON SARS-CoV-2 Ag assay is a two-step sandwich fully automated chemiluminescence immunoassay (CLIA) for the quantitative determination of SARS-CoV2 nucleocapsid $(\mathrm{N})$ antigen protein in nasopharyngeal swabs on the LIAISON ${ }^{\circledR}$ XL Analyzer (DiaSorin, Saluggia, Italy). The assay was performed according to the manufacturer's recommendations. The light signal, and hence the amount of isoluminol-antibody conjugate, is measured by a photomultiplier in relative light units (RLU) $\left(\mathrm{TCID}_{50} / \mathrm{mL}\right)$ and indicates the presence or absence of the SARS-CoV-2 Ag in samples.

\subsection{Statistical Analysis}

RT-qPCR was considered as the gold standard for this evaluation, therefore, positive and negative samples by molecular techniques were considered to be true positive and true negative samples, respectively. Sensitivity, specificity, positive and negative predictive values with corresponding 95\% confidence intervals (CI) were calculated to assess diagnostic performance. Student $t$ and Mann-Whitney $\mathrm{U}$ tests were used to assess differences between groups. Categorical variable was compared using Chi-square test. The area under the receiver operating characteristics curves (AUC of ROC) and their $95 \%$ confidence intervals (CIs), were used to evaluate the diagnostic value of the LIAISON SARS-CoV-2 Ag assay. A simple linear regression was performed to assess the potential correlation between antigen level obtained on the automated LIAISON ${ }^{\circledR}$ SARS-CoV-2 antigen test and RT-qPCR Ct values. All $p$-values were two-sided and $p$ less than 0.05 was considered significant. Statistical analyses were performed using GraphPad PRISM version 6.0e (GraphPad Software, San Diego, CA, USA) or MedCalc statistical software.

\section{Results}

\subsection{Sensitivity and Specificity of the Automated LIAISON ${ }^{\circledR}$ SARS-CoV-2 Antigen Test}

We randomly sampled 300 nasopharyngeal specimens. According to RT-qPCR results, 150 specimens were positive collected from asymptomatic and symptomatic patients and 150 were negative. The demographic and clinical characteristics of the study subjects are shown in Table 1. Vaccinated persons received two doses of Pfizer-BioNTech's messenger RNA-based vaccine (BNT162b2), or ChAdOx1 nCoV-19 vaccine, Oxford/AstraZeneca's non-replicating viral-vectored vaccine. There was no significant difference between the proportions of vaccinated people (53.3\%) with symptoms and unvaccinated patients $(46.7 \%)$ $(p=0.766)$.

Among the 150 positive samples by RT-qPCR, 113 were positive for SARS-CoV-2 $\mathrm{Ag}$ according to the manufacturer interpretation rules $\left(<100 \mathrm{TCID}_{50} / \mathrm{mL}\right.$ for negative, $100-199.99 \mathrm{TCID}_{50} / \mathrm{mL}$ for equivocal, and $\geq 200 \mathrm{TCID}_{50} / \mathrm{mL}$ for positive sample). The diagnostic accuracy of COVID-19 using SARS-CoV-2 Ag was performed (Table 2). Using NPS RT-qPCR as the reference method, the sensitivity of SARS-CoV-2 Ag for the diagnosis of COVID-19 in nasopharyngeal swabs was $75.33 \%$ (95\% CI: 67.64-82). Among the 39 false negative samples, ten were located in the $100-199.99 \mathrm{TCID}_{50} / \mathrm{mL}$ range defined by the manufacturer as equivocal, while 29 were negative $\left(<100 \mathrm{TCID}_{50} / \mathrm{mL}\right)$. Among the 150 negative samples by RT-qPCR, 150 were negative for SARS-CoV-2 antigen detection, meaning an overall specificity of 100\% (95\% CI: 97.57-100). A deep assessment was performed and summarized in Table 2.

The mean level of SARS-CoV-2 Ag among the RT-qPCR positive samples was significantly higher $\left(34,202 \pm 3395 \mathrm{TCID}_{50} / \mathrm{mL}\right)$ than that of the RT-qPCR negative samples $\left(41.44 \pm 2.08 \mathrm{TCID}_{50} / \mathrm{mL}\right)(p<0.0001)$ (Figure 1a). ROC curve analysis was performed to determine the area under the curve (AUC) of the antigen level allowing the distinction of SARS-CoV-2 infection status. The AUC of the assay was 0.94 (95\% CI, $0.91-0.96 ; p<0.0001$ ) indicating a very good performance (Figure $1 b$ ). 
Table 1. Demographic and clinical characteristics of subjects.

\begin{tabular}{ccc}
\hline & $\begin{array}{c}\text { RT-qPCR Positive Patients } \\
(\mathbf{N}=\mathbf{1 5 0 )}\end{array}$ & $\begin{array}{c}\text { RT-qPCR Negative Subjects } \\
(\mathbf{N}=\mathbf{1 5 0})\end{array}$ \\
\hline Median age (range), year & $34(4-74)$ & $43(7-79)$ \\
\hline Sex, no. (\%) & $54(36)$ & $84(56)$ \\
\hline Male & $96(64)$ & $66(44)$ \\
\hline Female & & \\
\hline $\begin{array}{c}\text { Presenting symptoms and } \\
\text { signs, no. (\%) }\end{array}$ & $12(8)$ & $6(4)$ \\
\hline Fever & $10(6.7)$ & $3(2.7)$ \\
\hline Headache & $14(9.3)$ & - \\
\hline Cough & $12(8)$ & $2(1.3)$ \\
\hline Generalised weakness & $9(6)$ & $3(2)$ \\
\hline Nasal congestion & $5(3.3)$ & $2(1.3)$ \\
\hline Sore throat & $10(6.7)$ & $2(1.3)$ \\
\hline Ageusia/ Anosmia & $3(2)$ & $44(29.3)$ \\
\hline Diarrhea & $7(4.7)$ & $47(31.3)$ \\
\hline Shortness of breath & $30(20)$ & \\
\hline COVID-19 vaccine, no. $(\%)$ & $29(19.3)$ & \\
\hline Pfizer-BioNTech & & \\
\hline ChAdOx1 nCoV-19 & & \\
\hline
\end{tabular}

a)

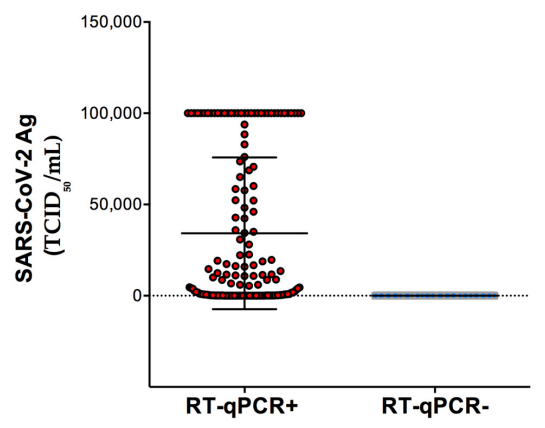

b)

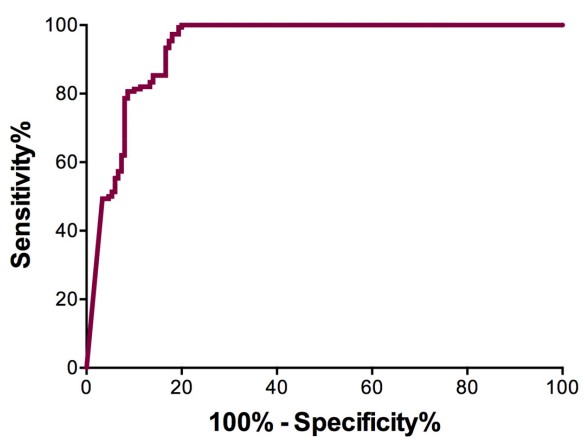

Figure 1. SARS-CoV-2 antigen detection according to RT-qPCR results. (a) The level of SARS-CoV-2 Ag among the RT-qPCR positive and negative samples. (b) Receiver operating characteristic (ROC) curve analysis to evaluate the diagnostic value of the LIAISON SARS-CoV-2 Ag assay. Data are presented as mean $\pm \mathrm{SD}$.

Table 2. Assessment of the diagnostic accuracy of the automated LIAISON ${ }^{\circledR}$ SARS-CoV-2 antigen test in nasopharyngeal swabs.

\begin{tabular}{ccc}
\hline & Value (\%) & $\mathbf{( 9 5 \% ~ C I ) ~}$ \\
\hline Sensitivity & 75.33 & $(67.64-82.00)$ \\
\hline Specificity & 100.00 & $(97.57-100.00)$ \\
\hline Negative likelihood ratio & 0.25 & $(0.19-0.3)$ \\
\hline Positive predictive value & 100 & $(92.32-99.13)$ \\
\hline Negative predictive value & 80.21 & $(75.40-84.28)$ \\
\hline Accuracy & 87.67 & $(83.40-91.17)$ \\
\hline
\end{tabular}




\subsection{Antigen Detection According to the RT-qPCR Ct Values}

Data analysis showed a good correlation between the antigen level and RT-qPCR Ct values (Figure 2).

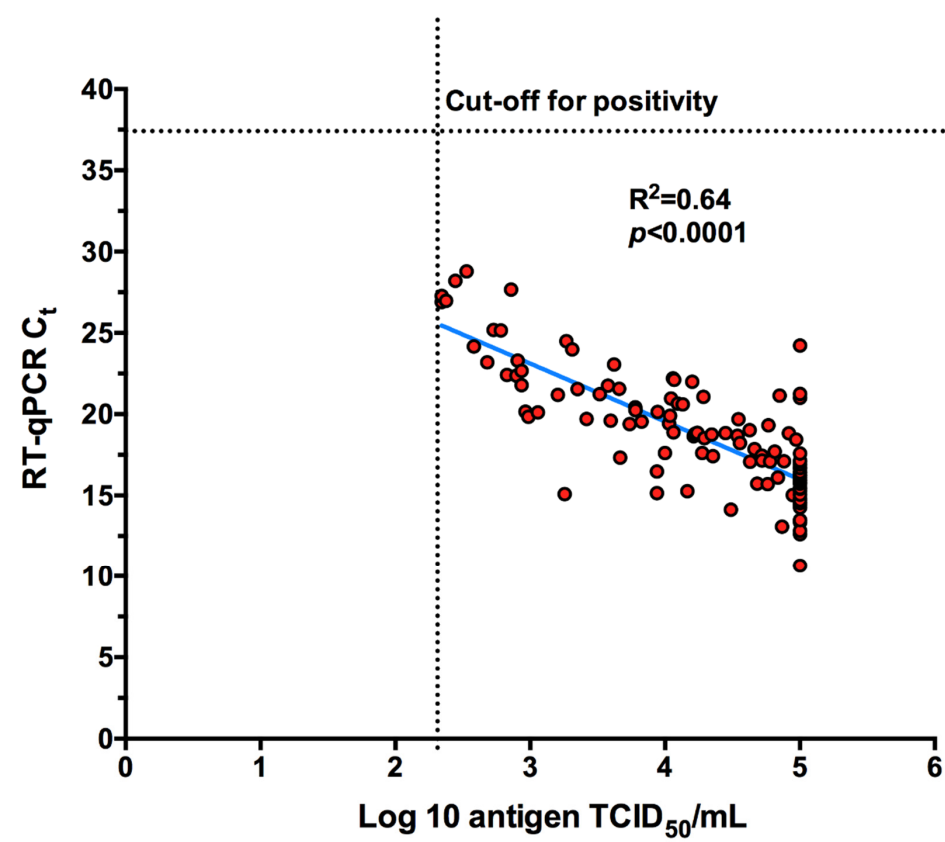

Figure 2. Linear regression of RT-qPCR Ct values versus the level of antigen (log10 transformed $\mathrm{TCID} 50 / \mathrm{mL}$ results) obtained on the DiaSorin LIAISON SARS-CoV-2 Ag assay.

The sensitivity was evaluated according to the $\mathrm{Ct}$ value. The viral load cut-off was applied to classify specimens as high viral load $(\mathrm{Ct}<18.57)$, medium viral load $(18.57<\mathrm{Ct}<$ 28.67) and low viral load (Ct $>28.67$ ) (based on the average $\mathrm{Ct}$ SARS-CoV-2 genes) (Table 3). The sensitivity of the SARS-CoV-2 Ag detection was $96.55 \%$ when considering samples with high viral load. The median level of SARS-CoV-2 Ag was 100,000 TCID $50 / \mathrm{mL}$ (range $1800-100,000 \mathrm{TCID}_{50} / \mathrm{mL}$ ). However, the sensitivity of the DiaSorin LIAISON SARS-CoV-2 Ag assay dropped to $6.67 \%$ for samples with low viral load (Table 3 ).

Table 3. Performance of the diagnostic accuracy of antigen detection according to the RT-qPCR Ct values.

\begin{tabular}{ccccccc}
\hline & & \multicolumn{3}{c}{ SARS-CoV-2 Antigen Detection } \\
\hline Viral Load & $\begin{array}{c}\text { Median Ct Value } \\
\text { (Range) }\end{array}$ & $n$ & Positive & $\begin{array}{c}\text { Median SARS-CoV-2 Ag Value } \\
\text { TCID }_{50} / \mathbf{m L} \text { (Range) }\end{array}$ & Sensitivity \\
\hline High & $15.94(10.65-18.53)$ & 58 & 56 & $100,000(1800-100,000)$ & $96.55 \%$ \\
\hline Medium & $22.29(18.64-28.52)$ & 77 & 56 & $5736(220-100,000)$ & $72.73 \%$ & $6.67 \%$ \\
\hline Low & $30.07(28.79-31.67)$ & 15 & 1 & 336 & $75.33 \%$ \\
\hline All & $19.90(10.65-31.67)$ & 150 & 113 & $25,353(220-100,000)$ & \\
\hline
\end{tabular}

\subsection{RT-qPCR, Antigen Detection and COVID-19 Vaccination}

The samples were classified according to the COVID-19 vaccination status (Table 1). The $\mathrm{Ct}$ values were analyzed in fully vaccinated and unvaccinated subjects according to viral loads (Figure 3a) and antigen quantification comparisons (Figure 3b). Interestingly, fully vaccinated individuals had relatively similar viral loads (Median PCR Ct $=19.60$ ) as unvaccinated individuals (Median PCR Ct $=19.70)(p=0.4215)$ (Figure 3a). Notably, the 113 positive subjects using automated LIAISON ${ }^{\circledR}$ SARS-CoV-2 antigen assay $\left(\mathrm{TCID}_{50} / \mathrm{mL} \geq 200\right)$ were stratified according to their vaccination status and data revealed no significant differ- 
ence between fully vaccinated and unvaccinated subjects regarding the level of SARS-CoV-2 $A g$ values (Figure $3 b$ ). In addition, stratification according to vaccine type showed no significant differences between Pfizer/BioNTech and ChAdOx1 nCoV-19 vaccines (Figure 3).

a)

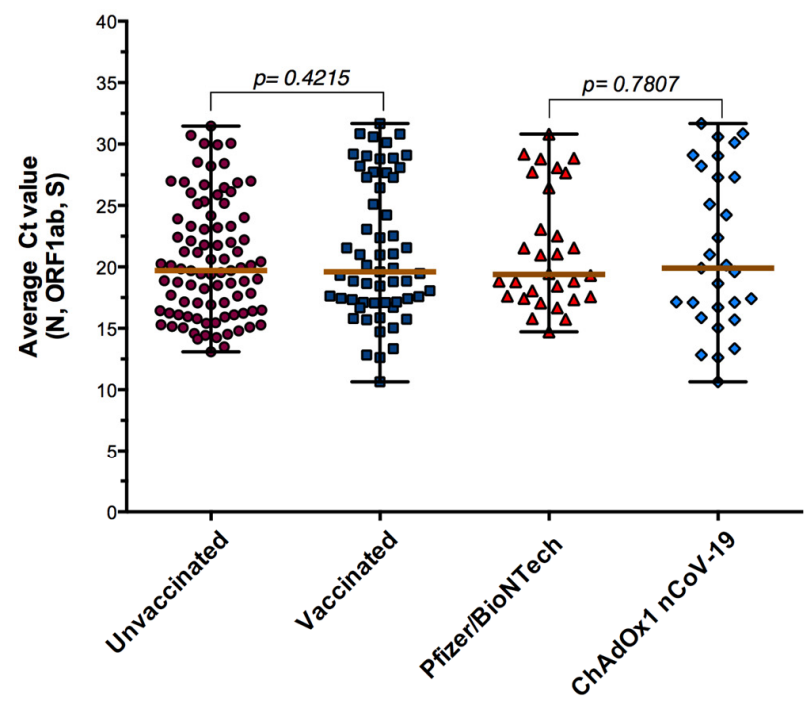

b)

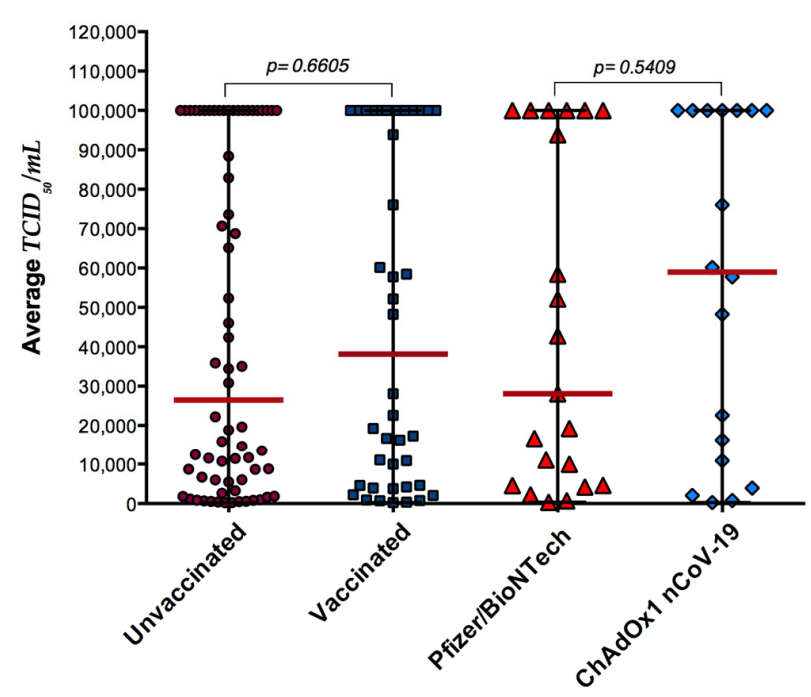

Figure 3. Cycle threshold (Ct) values for PCR-positive infections by vaccination status and type of vaccine. (a) Data are presented as RT-qPCR Ct values. (b) Data are presented as SARS-CoV-2 antigen levels obtained on the DiaSorin LIAISON SARS-CoV-2 Ag assay. Data are presented as median with range.

\section{Discussion}

Viral nucleic acid detection using an RT-qPCR assay remains the standard diagnosis tool of COVID-19. While this detects a large number of the suspected and contact cases with typical clinical COVID-19 features, other alternative diagnostic approaches are needed. The SARS-CoV-2 antigen diagnostic assays have been widely used to help diagnosis virus infection. Compared to the RT-qPCR assay, the automated LIAISON SARS-CoV-2 $\mathrm{Ag}$ is often faster (around $42 \mathrm{~min}$ ), less expensive, easier to use and accessible to staff without laboratory training. In addition, the detection ability of the $\mathrm{N}$ antigen by the DiaSorin LIAISON SARS-CoV-2 Ag is not theoretically impacted by the recently emerged variants of concern, which harbor different mutations in the spike protein [22,23]. Here, we evaluated the performance characteristics of the DiaSorin LIAISON SARS-CoV-2 Ag assay for detecting SARS-CoV-2 in respiratory specimens and compared the results with RT-qPCR (the gold standard assay). The sensitivity and specificity of this assay for the detection of SARS-CoV-2 were presented and the clinical application of this assay for the diagnosis of COVID-19 was discussed.

The overall sensitivity of DiaSorin LIAISON SARS-CoV-2 Ag assay was evaluated to be $75.33 \%$ and the specificity reached $100 \%$. Previous investigations of the LIAISON SARS-CoV-2 Ag test showed an overall sensitivity ranging from 31 to $84.8 \%$ and specificity of $\approx 100 \%$ at the $200 \mathrm{TCID}_{50} / \mathrm{mL}$ manufacturer's cut-off [5,24-26], whereas, when applying the cut-off at $82 \mathrm{TCID}_{50} / \mathrm{mL}$, a previous report showed that the sensitivity of the DiaSorin LIAISON SARS-CoV-2 Ag test yielded 73\% sensitivity [26]. Moreover, similar automated antigenic assays have previously been evaluated and exhibited sensitivity ranging from $70 \%$ to $97 \%[21,22,27-33]$.

In this study, the diagnostic performance of the novel DiaSorin LIAISON SARS-CoV-2 Ag chemiluminescence immunoassay suggests a higher performance in samples collected in the early phase of infection with high viral loads (i.e., $\mathrm{Ct}$ values $\mathrm{Ct}<18.57$ ) and displaying $96.55 \%$ sensitivity. These data seem to be in line with previous studies $[7,21,24,26,31,34]$. 
A major finding in our study is a comparison of $\mathrm{Ct}$ values and LIAISON SARS-CoV-2 Ag levels highlighting no significant differences between vaccinated and unvaccinated individuals in term of viral RNA loads and SARS-CoV-2 Ag levels, suggesting the same transmission potential. These data seem to be in line with several previous investigations showing no significant differences between vaccinated and unvaccinated groups, with significant breakthrough infections of SARS-CoV-2 variants in fully vaccinated people [33,35-41]. However, previous studies showed that COVID-19 vaccines attenuated the SARS-CoV-2 RNA loads, indicating a reduced infectiousness and virus transmissibility $[17,18,42]$.

\section{Conclusions}

This study showed that the automated DiaSorin LIAISON SARS-CoV-2 antigen test has good sensitivity and specificity for identifying patients with high SARS-CoV-2 viral load and at high risk of being active sources of contagion. However, the sensitivity level does not allow for exclusion of the risk that subjects testing negative may still carry the active SARS-CoV-2 virus. Thus, more investigations are warranted by companies to improve its sensitivity in order to reduce false negative results regarding samples with low viral loads. Notably, no significant differences were observed between vaccinated and unvaccinated subjects in terms of viral loads and SARS-CoV-2 Ag levels. Thus, booster vaccinations in groups at high risk of severe COVID-19 should be recommended to help reduce the burden of COVID-19 and to improve vaccination responses.

In summary, DiaSorin's LIAISON SARS-CoV-2 antigen is an inexpensive assay and an ideal test for high-throughput and decentralized screening of subjects with high SARSCoV-2 viral loads for the early identification and isolation of COVID-19 patients.

Author Contributions: Conceptualization, H.A. and S.E.; methodology, H.A., W.A. and T.A.-F.; validation and data curation, H.A., S.E. and W.A.; formal analysis, H.A. and S.E.; writing-original draft preparation and writing-review and editing, H.A.; project administration and funding acquisition. All authors have read and agreed to the published version of the manuscript.

Funding: This research was funded by the AnaSalbi laboratory and the Ministry of Health, Kuwait.

Institutional Review Board Statement: The study was conducted according to the guidelines of the Declaration of Helsinki, and approved by the permanent Committee for Coordination of Medical and Health Research, Ministry of Health, Kuwait.

Informed Consent Statement: Informed consent was obtained from all subjects involved in the study.

Data Availability Statement: Data supporting reported results are available from the corresponding author on reasonable request.

Conflicts of Interest: The authors declare no conflict of interest.

\section{References}

1. Kucharski, A.J.; Klepac, P.; Conlan, A.J.K.; Kissler, S.M.; Tang, M.L.; Fry, H.; Gog, J.R.; Edmunds, W.J.; Emery, J.C.; Medley, G.; et al. Effectiveness of isolation, testing, contact tracing, and physical distancing on reducing transmission of SARS-CoV-2 in different settings: A mathematical modelling study. Lancet Infect. Dis. 2020, 20, 1151-1160. [CrossRef]

2. Phua, J.; Weng, L.; Ling, L.; Egi, M.; Lim, C.M.; Divatia, J.V.; Shrestha, B.R.; Arabi, Y.M.; Ng, J.; Gomersall, C.D.; et al. Intensive care management of coronavirus disease 2019 (COVID-19): Challenges and recommendations. Lancet Respir. Med. 2020, 8, 506-517. [CrossRef]

3. Kevadiya, B.D.; Machhi, J.; Herskovitz, J.; Oleynikov, M.D.; Blomberg, W.R.; Bajwa, N.; Soni, D.; Das, S.; Hasan, M.; Patel, M.; et al. Diagnostics for SARS-CoV-2 infections. Nat. Mater. 2021, 20, 593-605. [CrossRef] [PubMed]

4. Ezzikouri, S.; Nourlil, J.; Benjelloun, S.; Kohara, M.; Tsukiyama-Kohara, K. Coronavirus disease 2019-Historical context, virology, pathogenesis, immunotherapy, and vaccine development. Hum. Vaccin Immunother. 2020, 16, 2992-3000. [CrossRef] [PubMed]

5. Lefever, S.; Indevuyst, C.; Cuypers, L.; Dewaele, K.; Yin, N.; Cotton, F.; Padalko, E.; Oyaert, M.; Descy, J.; Cavalier, E.; et al. Comparison of the Quantitative DiaSorin Liaison Antigen Test to Reverse Transcription-PCR for the Diagnosis of COVID-19 in Symptomatic and Asymptomatic Outpatients. J. Clin. Microbiol. 2021, 59, e0037421. [CrossRef] [PubMed] 
6. Haage, V.C.; de Ferreira Oliveira-Filho, E.; Moreira-Soto, A.; Kühne, A.; Fischer, C.; Sacks, J.A.; Corman, V.M.; Müller, M.A.; Drosten, C.; Drexler, J.F. Impaired performance of SARS-CoV-2 antigen-detecting rapid diagnostic tests at elevated and low temperatures. J. Clin. Virol. 2021, 138, 104796. [CrossRef] [PubMed]

7. Mak, G.C.; Lau, S.S.; Wong, K.K.; Chow, N.L.; Lau, C.S.; Lam, E.T.; Chan, R.C.; Tsang, D.N. Analytical sensitivity and clinical sensitivity of the three rapid antigen detection kits for detection of SARS-CoV-2 virus. J. Clin. Virol. 2020, 133, 104684. [CrossRef]

8. $\quad$ Lindner, A.K.; Nikolai, O.; Kausch, F.; Wintel, M.; Hommes, F.; Gertler, M.; Krüger, L.J.; Gaeddert, M.; Tobian, F.; Lainati, F.; et al. Head-to-head comparison of SARS-CoV-2 antigen-detecting rapid test with self-collected nasal swab versus professional-collected nasopharyngeal swab. Eur. Respir. J. 2021, 57, 2003961. [CrossRef]

9. Altawalah, H.; AlHuraish, F.; Alkandari, W.A.; Ezzikouri, S. Saliva specimens for detection of severe acute respiratory syndrome coronavirus 2 in Kuwait: A cross-sectional study. J. Clin. Virol. 2020, 132, 104652. [CrossRef]

10. Corman, V.M.; Haage, V.C.; Bleicker, T.; Schmidt, M.L.; Mühlemann, B.; Zuchowski, M.; Jo, W.K.; Tscheak, P.; Möncke-Buchner, E.; Müller, M.A.; et al. Comparison of seven commercial SARS-CoV-2 rapid point-of-care antigen tests: A single-centre laboratory evaluation study. Lancet Microbe 2021, 2, e311-e319. [CrossRef]

11. Baro, B.; Rodo, P.; Ouchi, D.; Bordoy, A.E.; Saya Amaro, E.N.; Salsench, S.V.; Molinos, S.; Alemany, A.; Ubals, M.; Corbacho-Monné, M.; et al. Performance characteristics of five antigen-detecting rapid diagnostic test (Ag-RDT) for SARS-CoV-2 asymptomatic infection: A head-to-head benchmark comparison. J. Infect. 2021, 82, 269-275. [CrossRef] [PubMed]

12. Dinnes, J.; Deeks, J.J.; Berhane, S.; Taylor, M.; Adriano, A.; Davenport, C.; Dittrich, S.; Emperador, D.; Takwoingi, Y.; Cunningham, J.; et al. Rapid, point-of-care antigen and molecular-based tests for diagnosis of SARS-CoV-2 infection. Cochrane Database Syst. Rev. 2021, 3, CD013705.

13. Polack, F.P.; Thomas, S.J.; Kitchin, N.; Absalon, J.; Gurtman, A.; Lockhart, S.; Perez, J.L.; Pérez Marc, G.; Moreira, E.D.; Zerbini, C.; et al. Safety and Efficacy of the BNT162b2 mRNA Covid-19 Vaccine. N. Engl. J. Med. 2020, 383, 2603-2615. [CrossRef] [PubMed]

14. Voysey, M.; Clemens, S.A.C.; Madhi, S.A.; Weckx, L.Y.; Folegatti, P.M.; Aley, P.K.; Angus, B.; Baillie, V.L.; Barnabas, S.L.; Bhorat, Q.E.; et al. Safety and efficacy of the ChAdOx1 nCoV-19 vaccine (AZD1222) against SARS-CoV-2: An interim analysis of four randomised controlled trials in Brazil, South Africa, and the UK. Lancet 2021, 397, 99-111. [CrossRef]

15. Bergwerk, M.; Gonen, T.; Lustig, Y.; Amit, S.; Lipsitch, M.; Cohen, C.; Mandelboim, M.; Levin, E.G.; Rubin, C.; Indenbaum, V.; et al. Covid-19 Breakthrough Infections in Vaccinated Health Care Workers. N. Engl. J. Med. 2021, 385, 1474-1484. [CrossRef] [PubMed]

16. Rovida, F.; Cassaniti, I.; Paolucci, S.; Percivalle, E.; Sarasini, A.; Piralla, A.; Giardina, F.; Sammartino, J.C.; Ferrari, A.; Bergami, F.; et al. SARS-CoV-2 vaccine breakthrough infections with the alpha variant are asymptomatic or mildly symptomatic among health care workers. Nat. Commun. 2021, 12, 6032. [CrossRef] [PubMed]

17. Thompson, M.G.; Burgess, J.L.; Naleway, A.L.; Tyner, H.; Yoon, S.K.; Meece, J.; Olsho, L.E.W.; Caban-Martinez, A.J.; Fowlkes, A.L.; Lutrick, K.; et al. Prevention and Attenuation of Covid-19 with the BNT162b2 and mRNA-1273 Vaccines. N. Engl. J. Med. 2021, 385, 320-329. [CrossRef] [PubMed]

18. Levine-Tiefenbrun, M.; Yelin, I.; Katz, R.; Herzel, E.; Golan, Z.; Schreiber, L.; Wolf, T.; Nadler, V.; Ben-Tov, A.; Kuint, J.; et al. Initial report of decreased SARS-CoV-2 viral load after inoculation with the BNT162b2 vaccine. Nat. Med. 2021, 27, 790-792. [CrossRef] [PubMed]

19. Despres, H.W.; Mills, M.G.; Shirley, D.J.; Schmidt, M.M.; Huang, M.L.; Jerome, K.R.; Greninger, A.L.; Bruce, E.A. Quantitative measurement of infectious virus in SARS-CoV-2 Alpha, Delta and Epsilon variants reveals higher infectivity (viral titer:RNA ratio) in clinical samples containing the Delta and Epsilon variants. medRxiv 2021. [CrossRef]

20. Hirotsu, Y.; Omata, M. SARS-CoV-2 B.1.1.7 lineage rapidly spreads and replaces R.1 lineage in Japan: Serial and stationary observation in a community. Infect. Genet. Evol. 2021, 95, 105088. [CrossRef]

21. Mak, G.C.K.; Lau, S.S.Y.; Wong, K.K.Y.; Chow, N.L.S.; Lau, C.S.; Ng, K.H.L.; Lam, E.T.K.; Chan, R.C.W.; Tsang, D.N.C. Evaluation of automated antigen detection test for detection of SARS-CoV-2. Diagn. Microbiol. Infect. Dis. 2021, 101, 115490. [CrossRef] [PubMed]

22. Gili, A.; Paggi, R.; Russo, C.; Cenci, E.; Pietrella, D.; Graziani, A.; Stracci, F.; Mencacci, A. Evaluation of Lumipulse ${ }^{\circledR}$ G SARS-CoV-2 antigen assay automated test for detecting SARS-CoV-2 nucleocapsid protein (NP) in nasopharyngeal swabs for community and population screening. Int. J. Infect. Dis. 2021, 105, 391-396. [CrossRef] [PubMed]

23. Altawalah, H. Antibody Responses to Natural SARS-CoV-2 Infection or after COVID-19 Vaccination. Vaccines 2021, 9, 910. [CrossRef]

24. Hartard, C.; Berger, S.; Josse, T.; Schvoerer, E.; Jeulin, H. Performance evaluation of an automated SARS-CoV-2 Ag test for the diagnosis of COVID-19 infection on nasopharyngeal swabs. Clin. Chem. Lab. Med. 2021, 59, 2003-2009. [CrossRef] [PubMed]

25. Häuser, F.; Sprinzl, M.F.; Dreis, K.J.; Renzaho, A.; Youhanen, S.; Kremer, W.M.; Podlech, J.; Galle, P.R.; Lackner, K.J.; Rossmann, H.; et al. Evaluation of a laboratory-based high-throughput SARS-CoV-2 antigen assay for non-COVID-19 patient screening at hospital admission. Med. Microbiol. Immunol. 2021, 210, 165-171. [CrossRef] [PubMed]

26. Salvagno, G.L.; Gianfilippi, G.; Fiorio, G.; Pighi, L.; De Nitto, S.; Henry, B.M.; Lippi, G. Clinical Assessment of the DiaSorin LIAISON SARS-CoV-2 Ag Chemiluminescence Immunoassay. EJIFCC Electron. J. Int. Fed. Clin. Chem. Lab. Med. 2021, 32, 216-223. [CrossRef] 
27. Aoki, K.; Nagasawa, T.; Ishii, Y.; Yagi, S.; Okuma, S.; Kashiwagi, K.; Maeda, T.; Miyazaki, T.; Yoshizawa, S.; Tateda, K. Clinical validation of quantitative SARS-CoV-2 antigen assays to estimate SARS-CoV-2 viral loads in nasopharyngeal swabs. J. Infect. Chemother. 2021, 27, 613-616. [CrossRef] [PubMed]

28. Iqbal, B.; Khan, M.; Shah, N.; Dawood, M.M.; Jehanzeb, V.; Shafi, M. Comparison of SARS-CoV-2 antigen electrochemiluminescence immunoassay to RT-PCR assay for laboratory diagnosis of COVID-19 in Peshawar. Diagnosis 2021, in press. [CrossRef]

29. Matsuzaki, N.; Orihara, Y.; Kodana, M.; Kitagawa, Y.; Matsuoka, M.; Kawamura, R.; Takeuchi, S.; Imai, K.; Tarumoto, N.; Maesaki, S.; et al. Evaluation of a chemiluminescent enzyme immunoassay-based high-throughput SARS-CoV-2 antigen assay for the diagnosis of COVID-19: The VITROS ${ }^{\circledR}$ SARS-CoV-2 Antigen Test. J. Med. Virol. 2021, 93, 6778-6781. [CrossRef] [PubMed]

30. Hirotsu, Y.; Sugiura, H.; Maejima, M.; Hayakawa, M.; Mochizuki, H.; Tsutsui, T.; Kakizaki, Y.; Miyashita, Y.; Omata, M. Comparison of Roche and Lumipulse quantitative SARS-CoV-2 antigen test performance using automated systems for the diagnosis of COVID-19. Int. J. Infect. Dis. 2021, 108, 263-269. [CrossRef] [PubMed]

31. Favresse, J.; Gillot, C.; Oliveira, M.; Cadrobbi, J.; Elsen, M.; Eucher, C.; Laffineur, K.; Rosseels, C.; Van Eeckhoudt, S.; Nicolas, J.B.; et al. Head-to-Head Comparison of Rapid and Automated Antigen Detection Tests for the Diagnosis of SARS-CoV-2 Infection. J. Clin. Med. 2021, 10, 265. [CrossRef]

32. Sberna, G.; Basile, F.; Guarino, M.L.; Capobianchi, M.R.; Bordi, L.; Parisi, G. Comparison of Allplex ${ }^{\mathrm{TM}}$ SARS-CoV-2 Assay, Easy SARS-CoV-2 WE and Lumipulse quantitative SARS-CoV-2 antigen test performance using automated systems for the diagnosis of COVID-19. Int. J. Infect. Dis. 2021, S1201-9712, 00781-00785. [CrossRef] [PubMed]

33. Vignier, N.; Bérot, V.; Bonnave, N.; Peugny, S.; Ballet, M.; Jacoud, E.; Michaud, C.; Gaillet, M.; Djossou, F.; Blanchet, D.; et al. Breakthrough Infections of SARS-CoV-2 Gamma Variant in Fully Vaccinated Gold Miners, French Guiana, 2021. Emerg. Infect. Dis. 2021, 27, 2673-2676. [CrossRef] [PubMed]

34. Paul, D.; Gupta, A.; Rooge, S.; Gupta, E. Performance evaluation of automated chemiluminescence immunoassay based antigen detection-Moving towards more reliable ways to predict SARS-CoV-2 infection. J. Virol. Methods 2021, 298, 114299. [CrossRef] [PubMed]

35. Luo, C.H.; Morris, C.P.; Sachithanandham, J.; Amadi, A.; Gaston, D.; Li, M.; Swanson, N.J.; Schwartz, M.; Klein, E.Y.; Pekosz, A.; et al. Infection with the SARS-CoV-2 Delta Variant is Associated with Higher Infectious Virus Loads Compared to the Alpha Variant in both Unvaccinated and Vaccinated Individuals. medRxiv 2021. [CrossRef]

36. Chau, N.V.V.; Ngoc, N.M.; Nguyet, L.A.; Quang, V.M.; Ny, N.T.H.; Khoa, D.B.; Phong, N.T.; Toan, L.M.; Hong, N.T.T.; Tuyen, N.T.K.; et al. An observational study of breakthrough SARS-CoV-2 Delta variant infections among vaccinated healthcare workers in Vietnam. EClinicalMedicine 2021, 41, 101143. [CrossRef]

37. Dash, G.C.; Subhadra, S.; Turuk, J.; Parai, D.; Rath, S.; Sabat, J.; Rout, U.K.; Kanungo, S.; Choudhary, H.R.; Nanda, R.R.; et al. Breakthrough SARS-CoV-2 infections among BBV-152 (COVAXIN ${ }^{\circledR}$ ) and AZD1222 (COVISHIELDT M ) recipients: Report from eastern state of India. J. Med. Virol. 2021, in press. [CrossRef]

38. Naito, T.; Yan, Y.; Tabe, Y.; Seyama, K.; Deshpande, G.A. Real-world evidence for the effectiveness and breakthrough of BNT162b2 mRNA COVID-19 vaccine at a medical center in Japan. Hum. Vaccin Immunother. 2021, 17, 1-2. [CrossRef]

39. Farinholt, T.; Doddapaneni, H.; Qin, X.; Menon, V.; Meng, Q.; Metcalf, G.; Chao, H.; Gingras, M.C.; Avadhanula, V.; Farinholt, P.; et al. Transmission event of SARS-CoV-2 delta variant reveals multiple vaccine breakthrough infections. BMC Med. 2021, 19, 255. [CrossRef]

40. Blanquart, F.; Abad, C.; Ambroise, J.; Bernard, M.; Cosentino, G.; Giannoli, J.M.; Débarre, F. Characterisation of vaccine breakthrough infections of SARS-CoV-2 Delta and Alpha variants and within-host viral load dynamics in the community, France, June to July 2021. Eurosurveillance 2021, 26, 2100824. [CrossRef]

41. Singanayagam, A.; Hakki, S.; Dunning, J.; Madon, J.K.; Crone, M.A.; Koycheva, A.; Derqui-Fernandez, N.; Barnett, L.J.; Whitfield, G.M.; Varro, R.; et al. Community transmission and viral load kinetics of the SARS-CoV-2 delta (B.1.617.2) variant in vaccinated and unvaccinated individuals in the UK: A prospective, longitudinal, cohort study. Lancet Infect. Dis. 2021. [CrossRef]

42. Singanayagam, A.; Patel, M.; Charlett, A.; Lopez Bernal, J.; Saliba, V.; Ellis, J.; Ladhani, S.; Zambon, M.; Gopal, R. Duration of infectiousness and correlation with RT-PCR cycle threshold values in cases of COVID-19, England, January to May 2020. Eurosurveillance 2020, 25, 2001483. [CrossRef] [PubMed] 